\title{
A OBJETIVIDADE DO CONHECIMENTO EM MAX WEBER ${ }^{1}$
}

Luis Henrique Paiva

A defesa da objetividade do conhecimento, em Weber, é um problema oriundo da difícil relação entre a concepção de realidade da qual parte e o fato de que "(...) ele guardou distância de tudo o que hoje em dia está sob o nome de relativismo" (Rickert, 1989, p. 79).

Weber parte de uma concepção de "realidade empírica" que problematiza qualquer idéia de "observação": assim, o autor acredita que a realidade empírica é "na sua plenitude, (...) inesgotável" (Weber, 1992a, p. 89) e "infinita" (1974, p. 47). O que, desta realidade, nos é permitido conhecer e observar, surge após um processo de seleção do material empírico, de modo que apenas um "fragmento limitado desta realidade poderá constituir de cada vez o objeto da compreensão científica" (1974, p. 47-8). Esta seleção, por não poder abarcar toda a realidade, é, necessariamente, parcial:

1Esse artigo corresponde ao primeiro capítulo de minha dissertação apresentada ao Mestrado em Sociologia do IFCH - UNICAMP, sob orientação do Prof. Dr. Octavio Ianni. 
Não existe qualquer análise científica "objetiva" da vida cultural, ou das "manifestações sociais", que seja independente de determinadas perspectivas especiais ou parciais, graças às quais estas manifestações possam ser, explícita ou implicitamente, consciente ou inconscientemente, selecionadas, para se tornarem objeto de investigação (...) (Weber, 1974, p. $46-7){ }^{2}$

o que abre a possibilidade do surgimento de uma pluralidade de interpretações possíveis.

Daí a pertinência da colocação de Runciman, segundo o qual

O que Weber fez (...) foi admitir a pluralidade das interpretações possíveis e, em seguida, fazer tudo o que estava ao seu alcance para reduzir as consequências deste fato (Runciman, s/d).

Este é o problema da objetividade do conhecimento para o autor: o de como tomar posição favorável à possibilidade da unicidade da verdade aceitando as idéias de realidade inesgotável e de multiplicidade de interpretações possíveis.

É interessante notar que este problema é, sem dúvida, o mais geral enfrentado pela epistemologia weberiana, pois os elementos que compõem a "situação de problema" - a saber, as idéias de "realidade inesgotável", de "multiplicidade possível de interpretações", e a posição crítica do relativismo - não dizem respeito exclusivamente às ciências sociais, mas a toda e qualquer ciência empírica. ${ }^{3}$

${ }^{2}$ Cf. também Weber (1974, p. 62; p. 63-4).

${ }^{3}$ Apesar da opinião contrária de alguns comentadores como Edmundo F. Dias, segundo o qual, para Weber, haveria uma "ordenação" entre acontecimentos estudados pelas ciências naturais, "ordenação que é própria da realidade e que independe relativamente do observador" (Dias, 1993, p. 9), e apenas as ciências sociais enfrentariam uma realidade que é "um conjunto inesgotável de acontecimentos", o próprio Weber apresenta opinião diversa: “(...) há uma 
Cabe aqui, antes de procurar especificar os caminhos seguidos pelo autor para o enfrentamento da questão, detalhar alguns de seus aspectos - especificamente aqueles que relacionam a idéia de "seleção" do material empírico aos valores e ao conceito "típico-ideal".

Weber percebeu que, se a seleção, no ato da análise científica, é compulsória, e se é o cientista que faz tal seleção, tal processo se vê marcado pela subjetividade. Os objetos assim definidos são "subjetivos" - pois definidos subjetivamente:
"Subjetiva" (...) é (...) a delimitação do "objeto" histórico mesmo, do "indivíduo" [histórico] mesmo, pois aqui deci- dem relações de valor cuja "concep̧̧ão" está submetida à mudança histórica (Weber, 1992b, p. 189).

Assim, através da subjetividade do cientista, ganham importância no processo de definição do objeto, valores do momento histórico e cultural vivido por esse cientista:
(...) em consonância com a experiência histórica, percebe-se que são os interesses culturais e, portanto, os interesses de va- lor que indicam a direção para o trabalho das ciências pura- mente empíricas (Weber, 1992d, p. 377). ${ }^{4}$

infinitude intensiva $\mathrm{em}$ toda variedade empiricamente dada que é, indiscutivelmente, o pressuposto (negativo) para a seleção do material que interessa para cada uma das ciências empiricas." (1992a, p. 54; a ênfase é minha). Esta visão equivocada da realidade natural (como ordenada "naturalmente") acaba por fazer Dias defender opiniões insustentáveis, como aquela em que afirma que “(...) a chamada ciência natural se caracteriza pelo fato de que a sua existência independe do que pensam os homens (...)" (1993, p. 11). Ora, qualquer tipo de ciência (natural ou social) é, antes de tudo, uma atividade dos homens, feita pelos homens, e especificamente humana. Cf., sobre isso, a posição clara de Parsons $(1968$, p. 716$)$.

${ }^{4}$ Cf. também Weber (1992b, p. 188).

Temáticas, Campinas, 3(5/6):9-36, jan./dez. 1995 
Essa influência de valores culturais determinados na definição do objeto é comumente chamada de "relação com valores", "referência a valores" ou "pertinência em relação aos valores" - e é baseada nas idéias de Rickert.

A seleção do objeto resulta no que Weber chamou de "tipo ideal": um conceito que levaria em conta as idéias de "realidade inesgotável" e de "multiplicidade de interpretações possíveis". Weber define o tipo ideal como resultado do processo de seleção, isto é, como resultado de uma

(...) acentuação unilateral de um ou vários pontos de vista e mediante o encadeamento de grande quantidade de fenômenos isoladamente dados, difusos e discretos, que se podem dar em maior ou menor número ou mesmo faltar por completo, e que se orientam segundo pontos de vista unilateralmente acentuados, a fim de formar um quadro de pensamento (Weber, 1974, p. 76).

O tipo é, portanto, "ideal", no sentido de que é um artefato analítico, um instrumento confeccionado pelo cientista para fins de conhecimento, distinto da realidade bruta:

(...) as construções teóricas [como os tipos] estão exclusivamente a serviço do conhecimento das realidades que elas mesmas não podem proporcionar. $E$ as realidades (...) não estão contidas naquelas construções teóricas e, mesmo no caso extremo, apresentam apenas aproximações do processo construído (Weber, 1992d, p. 396).

E se Weber coloca o tipo ideal como um instrumento compulsório,

Se o historiador (...) abandona a tentativa de formular um tal tipo ideal sob o pretexto de constituírem "construções teóricas" (...) resulta então, regra geral, que este historiador utiliza, consciente ou inconscientemente, outras construções análogas sem as formular explicitamente (...) (Weber, 1974, p. 82), 
é porque o ato de selę̧ão, para efeito de conhecimento, é compulsório, e o tipo ideal é o conceito que resulta desse ato de seleção. ${ }^{5}$

Tais tipos não são úteis por si, mas pela possibilidade que abrem para a construção de hipóteses bistóricas causais:

"Embora não seja uma 'hipótese', [o tipo-ideal] pretende apontar o caminho para a formação de hipóteses. Embora não seja um enunciado do real, pretende conferir a esse enunciado meios inequivocos de expressão" (Weber, 1974, p. 75-6. A ênfase na frase final é minha).

E é em relação a essas bipóteses - construídas com o auxílio de conceitos que selecionam, na realidade empírica dada, objetos que se julga dignos de interesse histórico - que se coloca o problema da objetividade do conhecimento. O problema é o de como assegurar a validade intersubjetiva dessas hipóteses.

Parsons bem notou que a admissão, por parte de Weber, da influência dos valores (através da "referência a valores") introduziu um elemento relativista que poderia pôr em questão a objetividade do conhecimento:

(...) o princípio da importância do valor, combinado com o da relatividade dos sistemas de valor, introduz um elemento

${ }^{5} \mathrm{Cohn}$ parece não ter notado isso quando aponta que Weber se equivoca quanto à obrigatoriedade do tipo ideal (Cohn, 1979, p. 130-1). Assim, Cohn afirma que o uso do tipo só se torna obrigatório caso se trabalhe com a premissa de realidade inesgotável. Acredito que, se a validade dessa premissa pode (e deve) ser debatida, seu uso não é "opcional": uma vez verdadeira, ela assim serviria de parâmetro para a avaliação de qualquer trabalho científico, tornando os tipos (ou conceitos que operam selecionando material empírico) um instrumento obrigatório. Weber, portanto, aponta para a compulsoriedade dos tipos ideais porque acredita na verdade da premissa da "realidade inesgotável".

Temáticas, Campinas, 3(5/6):9-36, jan./dez. 1995 
de relatividade nas ciências sociais, que suscita de forma aguda a questão de suas pretensões de objetividade (Parsons, 1968, p. 730).

E aqui entramos propriamente no terreno do que Weber chamou de "objetividade do conhecimento" científico. Para ele, tal objetividade se configuraria na validação intersubjetiva de um conhecimento. $\mathrm{O}$ autor, admitindo que a "relação com valores" influi diretamente na definição do objeto de pesquisa (que é, assim, subjetivo), acredita, entretanto, que os resultados da pesquisa podem ser objetivos:

Torna-se indubitável que as idéias de valor são "subjetivas". (...) No entanto, não devemos deduzir de tudo isso que a in. vestigação científico-cultural apenas conseguiria obter resultados "subjetivos", no sentido de que são válidos para uns e não para outros. (...) Porque só é uma verdade científica aquilo que pretende ser válido para todos os que querem a verdade (Weber, 1974, p. 65-6).

Weber não propõe qualquer "esquema formalizado de validação" dos conhecimentos empíricos e históricos apresentados como hipóteses por pesquisadores, mas sugere alguns critérios para essa validação ao longo de sua obra. Cohn procura a resposta para a questão da objetividade do conhecimento em Weber centrando a atenção na construção dos tipos ideais:

(...) o problema se concentra (...) na questão dos critérios que comandam as operações de isolamento e depuração de aspectos da realidade histórico-social. Em consonância com isso, Weber dedica atenção (...) às questões relacionadas ao caráter construtivo do tipo (Cohn, 1979, p. 50).

O autor está correto - muito embora a preocupação com a construção do tipo ideal, sustentarei, responde apenas parcialmente o problema da objetividade do conhecimento. 
Para que entendamos de maneira correta esse ponto, nos deteremos em destaques dados por Weber à construção do tipo ideal. São três as questões que Weber pretende esclarecer, partindo da compulsoriedade do tipo ideal.

A primeira das questões aponta para o fato de que, com a falta de cuidado na admissão de que os conceitos operam uma seleção do material empírico, tende-se a fazer a seleção (que é, como vimos, compulsória) de forma não controlada, tornando-a "imprecisa" e afetando a clareza da exposição. Logo, assegura Weber, todo cuidado deve ser tomado no sentido de que os conceitos não tenham um "impreciso caráter do seu conteúdo" (Weber, 1974, p. 80).

O conceito que não é construído de forma clara, inequívoca e rigorosa (como os conceitos que utilizamos cotidianamente), segundo o autor,

(...) oculta sempre confusões do pensamento ou da vontade, muitas vezes é o instrumento de perigosas ilusões, e é constantemente o meio de boicotar a evolução de uma exposição correta dos problemas (Weber, 1974, p. 107-8).

Portanto, "(...) é apenas mediante a construção rigorosa dos conceitos, ou seja, graças à utilização do tipo ideal, que se torna possível expor de forma inequívoca o que se entende e pode entender" pelo significado de algum conceito (1974, p. 84).

O primeiro dos motivos, portanto, para que se controle a construção dos tipos ideais (de forma logicamente não-contraditória e conceitualmente rigorosa) é garantir a clareza e a expressão inequívoca dos conceitos.

Weber exemplifica bem o que quer dizer ao examinar alguns conceitos que, se a princípio parecem "claros" (uma vez que relativamente familiares), englobam toda sorte de contradições que se revelam mesmo num exame rápido. Um dos conceitos utilizados para esse fim é 
o de "interesses da lavoura". Toda sorte de interesses contraditórios se engloba em tais conceitos, tais como
(...) os interesses dos camponeses que desejam vender suas terras, pelo que apenas lhes interessa uma rápida subida no preço dos terrenos; o interesse diametralmente oposto daque- les que querem comprar terras, aumentá-las ou tomá-las de arrendamento; o interesse dos que estão empenhados em conservar uma propriedade para obterem vantagens sociais para os seus descendentes, pelo que estão interessados numa estabilização da propriedade; o interesse contrário desses ou- tros que, no interesse próprio ou dos seus filhos, desejam uma redistribuição das terras em benefício do que melhor as explora (...) (Weber, 1974, p. 104).

Desnecessário dizer que a falta de rigor nesta construção conceitual - e em outras, segundo Weber, como "interesses do Estado" ou mesmo "interesses da classe operária" - impede a clareza da exposição que se faz com a sua utilização.

Outro perigo de se ignorar a compulsoriedade da seleção do material empírico, e passo aqui para o exame da segunda questão, é operar tal seleção admitindo uma confusão entre a influência lógica dos valores e a influência prática dos valores. Como vimos, o princípio de seleção do material empírico sugerido por Weber são as idéias de valor. Se não tomarmos o necessário cuidado com a utilização de tais idéias de valor - cuidados esses claros quando se tem consciência da compulsoriedade da seleção que faz qualquer conceito -, poderemos criar um tipo que não seja ideal apenas no sentido lógico mas também no sentido prá. tico, isto é, que corresponda a alguma desejada efetivação prática de nossas idéias de valor, ou ao que acreditamos que o fenômeno deve 'idealmente' ser. ${ }^{6}$ Desta forma, é necessário distinguir drasticamente

${ }^{6}$ Como diz Weber para contraditar tal idéia, existem tipos ideais tanto de religiões como de bordéis... 
nossos conceitos da realidade - mesmo que existam aproximações e mesmo sabendo que o dever da atividade científica seja medir tais aproximações.

Chegamos, com isso, à terceira das questões, que trata da radical distinção feita por Weber entre o conceito e a realidade empírica. Essa distinção deve ser entendida não como a afirmação de que todo trabalho científico seja uma desmesurada obra de ficção, mas como uma (saudável, no meu entender) atitude cética com relação a todo e qualquer conhecimento. O tipo ideal, assim,

(...) revela um ponto de vista teórico e portanto 'unilateral' que, embora esclareça a realidade, demonstra ser impróprio para se tornar um esquema no qual essa realidade pudesse ficar completamente incluída. Porque nenhum desses esquemas mentais (...) pode esgotar a sua imensa riqueza. Todos esses sistemas não passam de tentativas para conferir uma ordem ao caos dos fatos que incluímos no âmbito do nosso in. teresse (...) (Weber, 1974, p. 99; ênfase do autor).

A forma correta do cientista lidar com essas três questões passa, obrigatoriamente, pelo controle da construção dos tipos ideais. É nesse sentido que Weber recomenda um "dever elementar de auto controle científico" (1974, p. 89) quando do "trabalho de construção e crítica dos conceitos". Entretanto, como o autor assevera, existem "outros meios" para que a prática científica atinja seu fim. ${ }^{7}$

${ }^{7}$ Interessante observar que justamente no texto sobre a "Objetividade do Conhecimento" Weber apenas coloque o problema da objetividade, não dando a ele a resposta geral que só iremos encontrar ao longo de sua obra. Assim, o autor afirma neste texto que "A 'objetividade' do conhecimento no campo das ciências sociais depende antes do fato de o empiricamente dado se encontrar constantemente alinhado sobre idéias de valor que são as únicas a conferir-lhe valor para o conhecimento (...)" (1974, p. 109, ênfase no original). Ora,

Temáticas, Campinas, 3(5/6):9-36, jan./dez. 1995 
Essas considerações weberianas permitem entender o quanto são importantes determinados aspectos formais da construção do tipo ideal para se atingir a objetividade do conhecimento. Definem tanto uma atitude cética em relação a todo conhecimento (quando aponta que se trata apenas de uma seleção "acentuada" de determinadas características do real - e não a própria realidade) como algumas condições necessárias para que se avalie um conhecimento como objetivo (rigor na construção conceitual, clareza de expressão etc.). Estas condições figuram certamente como necessárias para que se decida sobre a objetividade do conhecimento: certamente é impossível tecer juízos de validade acerca de algo que não se compreende por ser vago, confuso ou contraditório.

Assim, como sugere Saint-Pierre, de fato Weber se preocupou com critérios de construção do tipo ideal:

O tipo-ideal é construído a partir de uma "intensificação unilateral" da realidade, ou seja, uma exageração de alguns de seus elementos característicos a partir de um determinado "ponto de vista". (...) tal construção deve satisfazer certas exigências formais, entre as quais figuram especialmente a consistência lógica e a não-contradição interna" (Saint-Pierre, 1991, p. 67. A ênfase é minha).

Mas esta não é a principal resposta à questão da objetividade do conhecimento dada por Weber. O descumprimento da exigência de "rigor" na construção do tipo ideal, por exemplo, pode impedir que um tipo ideal qualquer seja considerado "válido". Seu cumprimento, entre-

esta não é a "solução" do problema da objetividade, senão sua colocação. A prova disso está no fato de que, imediatamente depois de fazer essa afirmação, Weber tivesse se sentido na obrigação de acrescentar que “(...) ainda que a significação desta objetividade apenas se compreenda a partir de tais idéias de valor, não se trata de converter isso em pedestal de uma prova empiricamente impossível da sua validade" (1974, p. 109).

Temáticas, Campinas, 3(5/6):9-36, jan./dez. 1995 
tanto, não garante ou assegura a validade do tipo. Idem para a exigência da distinção entre tipo e realidade: caso não seja observada, tal exigência pode produzir um conjunto de conceito confusos - mas sua observância não garante a validade a priori dos conceitos.

A preocupação com a construção dos tipos ideais, além disso, não resolve uma questão de maior fôlego: a de como se decide a respeito da validade de uma hipótese causal determinada. ${ }^{8}$ Uma hipótese causal que relacionasse dois tipos ideais históricos (como "protestantismo" e "corporativismo") - isto é, que tomasse, por exemplo, as práticas corporativas de parcelas significativas da sociedade alemã atual como determinadas (ou influenciadas) por crenças centrais específicas das doutrinas protestantes vigentes na mesma sociedade - poderia ter seus tipos construídos de forma a respeitar as exigências formais de consistência lógica e não-contradição interna e, ainda assim, não ser válida. Os tipos, construídos corretamente, poderiam não se mostrar úteis.

As exigências formais para a construção dos tipos ideais é feita por Weber, mas não constitui sua principal resposta para o problema da validação intersubjetiva (e, portanto, da objetividade) do conhecimento.

Para que se entenda como Weber procura enfrentar o problema da objetividade do conhecimento, teremos que passar por uma distinção feita por ele (mas nomeada e presente nos debates metodológicos nos dias de hoje): a distinção entre o contexto da descoberta e o contexto da validação. Assim, a origem (e, portanto, a "descoberta") de um conhecimento não é, para Weber, questionável. Weber não acredita que

${ }^{8}$ Uma vez que, como foi mencionado, os tipos não são o fim da atividade científica: eles servem à construção de hipóteses históricas, isto é, ao conhecimento da realidade histórica. A validade do tipo não garante, infelizmente, a validade da hipótese, como veremos logo a seguir.

Temáticas, Campinas, 3(5/6):9-36, jan./dez. 1995 
exista um "método de abordagem particular", ou um "processo psicológico específico" "que resulte, com certeza, em conceitos e hipóteses válidos ou objetivos. O autor afirma, por exemplo, que

Cientificamente, a idéia de um diletante pode ter a mesma influência, ou ainda maior, para a ciência que a idéia de um especialista. Muitas de nossas melhores hipóteses e visões são devidas, precisamente, a diletantes (Weber, 1982, p. 161).

A validação de um conhecimento, portanto, é feita a posteriori, através do questionamento desse conhecimento por diversos meios (como o exame dos critérios formais acima mencionados, a experimentação e o teste, a recorrência a dados empíricos históricos etc.). Nunca se deveria, portanto, fazer

(...) com que a pergunta quanto ao processo psicológico na formação de um conhecimento fosse confundida com a pergunta quanto ao "sentido" lógico da sua validade empírica (Weber, 1992a, p. 82)..$^{10}$

É importante acentuar que a regra da validação também não marcaria a diferença entre as ciências sociais e as ciências naturais:

9Tal como o "esvaziar as mentes" dos positivistas. Os passos para a construção do tipo ("acentuar unilateralmente aspectos da realidade...") apontam apenas para a produção de um tipo, mas não garante que seja um tipo frutífero para pesquisa, ou uma hipótese causal correta etc.

${ }^{10} \mathrm{Em}$ outra passagem, Weber diz que “(...) não queremos afirmar nada sobre a questão psicologicamente interessante mas da qual não nos ocupamos aqui: como é que surge uma hipótese histórica na mente do pesquisador, mas somente com referência à questão de em que categoria lógica em caso de dúvida e de questionamento é possível demonstrar a validade de tal hipótese (...)" (1992b, p. 202; a ênfase é minha).

Temáticas, Campinas, 3(5/6):9-36, jan./dez. 1995 
O uso de determinadas "regras" na "validação empírica", tendo por fim o controle da "interpretação" das ações humanas, apenas poderia ser tido como diferente do procedimento nas "ciências naturais" quando se aborda essa questão de modo assaz superficial (Weber, 1992a, p. 82).

Isso é central no que entendo ser a epistemologia weberiana - ao menos no que tange à questão da objetividade do conhecimento. A distinção entre o contexto da descoberta e o contexto da validação permite a Weber uma solução teórica para o impasse anteriormente mencionado: a influência dos valores e da subjetividade do cientista na definição do objeto de pesquisa e seu conceito, na criação de hipóteses e hipóteses de trabalho, na condução de toda pesquisa - influência que torna problemática a questão da objetividade do conhecimento e que não é, de forma alguma, eliminada pelo processo rigoroso de construção dos conceitos -, por um lado, passa a pertencer ao plano da descoberta. A validação do conhecimento resultante, por outro, se dá através dos meios acima mencionados: julga-se não apenas se ele está de acordo com os critérios formais (se é logicamente consistente, não-contraditório), mas também com as evidências históricas existentes, etc.

Essa verificação não precisa ser, necessariamente, feita pelo próprio cientista, podendo sê-lo no debate científico: daí a definição de objetividade do conhecimento como a validação intersubjetiva desse mesmo conhecimento. ${ }^{11}$ Assim, um conhecimento cuja produção foi

${ }^{11}$ Não são raras as menções de Weber à "discussão livre" (1992c, p. 212) ou à falibilidade de todo conhecimento científico (1982, p. 164). Assim, pode-se considerar que o exame de um conhecimento exige, para Weber, um certo distanciamento por parte do cientista, para que se possa perceber nele seus equívocos. Jaspers afirma, a respeito do espírito crítico weberiano que "Há uma tendência indestrutível da vontade não crítica de conhecer (...). E contra esse impulso monístico que se volta o conhecimento crítico de Max Weber" (Jaspers, 1977, p. 129).

Temáticas, Campinas, 3(5/6):9-36, jan./dez. 1995 
influenciada por valores pode ser objetivo, caso passe pelos diversos exames que os cientistas impõem. ${ }^{12}$ Essa idéia weberiana foi corretamente percebida por Saint-Pierre:

(...) embora se parta de uma escolha subjetiva para o recorte do material, os resultados científicos (...) devem ser obtidos a partir de procedimentos submetidos à verificação, e cuja correção se imponha sobre todos os pontos de vista e a quaisquer sistemas de valores. O que Weber está exigindo desse modo é correção metodológica (critério interno) e posterior correção empírica dos resultados (critério externo), que é o que pretende uma ciência empírica da realidade cultural (SaintPierre, 1991, p. 39, a ênfase é minha).

Dois possíveis tipos de critérios de validação são sugeridos por Weber (além dos critérios "formais"): os que dizem respeito à validade $\mathrm{e}$ utilidade dos tipos ideais e os que dizem respeito à validade das hipóteses históricas empíricas propostas pelos cientistas.

${ }^{12}$ Não estou sugerindo que Weber apresente, aqui, uma clara teoria dos "aspectos sociais do progresso científico", ou que dedique muita atenção ao tema da "comunidade científica". Não que Weber efetivamente não tenha se importado com o tema: um dos seus importantes textos "metodológicos" ("A Ciência como Vocação") fala exatamente da comunidade científica. Em diversas oportunidades, cf. citação anterior, Weber se mostra um defensor do "espírito crítico" e um crítico do academicismo tacanho (idéias que dizem respeito à comunidade acadêmica e científica, esta é a verdade). Lembro-me, por exemplo, de uma passagem de seu texto sobre a "Objetividade do Conhecimento" em que afirma que a Archiv "não protegerá ninguém - nem os seus colaboradores, nem os seus editores - de se expor (...) à mais dura crítica científica e objetiva" (Weber, 1974, p. 27). De qualquer maneira, é meu dever reafirmar que Weber não possui uma teoria sistematizada dos aspectos sociais do conhecimento científico, nem uma teoria do "racionalismo crítico", que só viriam a aparecer com Popper. Tais temas não são, entretanto, estranhos ao autor.

Temáticas, Campinas, 3(5/6):9-36, jan./dez. 1995 
Um critério de validação a posteriori dos tipos ideais é sugerido por Jeferson Soares (1992), por ele nomeado "princípio de demonstrabilidade":

(...) a demonstrabilidade da 'verdade' ou validade de conceitos-tipo ou teorias (leis sociais) está em função do seu poder de ordenar a realidade social. Nesse sentido, se um conceitotipo é capaz de ordenar o real social (a realidade histórica), então, podemos alegar que é 'verdadeiro' ou válido, ou seja, é pertinente ou tem significado empiricamente demonstrável (Soares, 1992, p. 75).

Um conceito tipo ideal, portanto, deveria ser considerado válido apenas quando se mostrasse ser um instrumento de seleção frutífero. Caso esse tipo não pudesse ser utilizado em determinadas situações, poder-se-ia substitui-lo por outro, sem que o primeiro deixasse de ser válido para outras situações. Soares ensaia uma crítica a esse princípio de demonstrabilidade: segundo ele, apesar do "princípio" não acarretar dogmatiza̧̧ão (uma vez que Weber admite o trabalho com uma pluralidade de tipos), acaba por implicar imunização contra a crítica, p. um tipo que não fosse útil numa situação histórica não seria "empiricamente falseado", mas apenas considerado inválido naquela situação histórica concreta. Soares, que pretende seguir Popper, não admite que conceitos não possam ser falseados empiricamente.

Este autor, de fato, apresenta um critério que está além dos critérios formais para que se decida acerca da validade do tipo ideal. Tal critério parece encontrar eco na obra do autor, pois, segundo Weber, os tipos ideais são meios de conhecimento - isto é, servem ao conhecimento por selecionar, na realidade empírica, aquilo que "deve" ser conhecido - e portanto para sabermos se se trata "de uma construção conceitual proveitosa para a ciência" existe um critério: "o da eficácia” (Weber, 1974, p. 79). Sua eficácia, entendo eu, é, portanto, função de algo pró- 
ximo do princípio de demonstrabilidade proposto por Soares, senão igual - isto é, de sua capacidade de ordenar a realidade. Sua crítica a Weber, entretanto, é equivocada, p. o próprio Popper admite que a metodologia trata de questões de validade acerca de enunciados, de hipóteses, e não de conceitos (Popper, 1989, p. 35-6). Assim, um conceito não pode ser falseado empiricamente - uma vez que se trata apenas de um instrumento de seleção do material empírico. Entretanto, as hipóteses causais nas quais tal conceito estiver presente, sim, podem ser falseadas e empiricamente questionadas - e com elas a teoria na qual se baseiam. ${ }^{13}$

O critério de validação para as hipóteses históricas empíricas propostas pelo cientista é, para Weber, o exame a partir dos dados empíricos existentes. Assim Weber não apenas propõe que “(...) o regresso causal apenas pode alcançar (...) validade se, em caso de questionamento, saiu honroso da prova (...)" (1992b, p. 202), como também assegura que qualquer que seja o conhecimento, "(...) seu alcance e sua validade devem ser examinadas pelos fatos empíricos" [evidentemente leia-se, no lugar de "pelos fatos empíricos", algo como "examinado através do recurso aos fatos empíricos"] (1992c, p. 222).

Eugène Fleishmann percebeu a importância que Weber dá à verificação empírica de hipóteses causais:

A chave da sua 'filosofia' deve ser procurada em uma tentativa incessante de 'verificar' suas idéias - pois sem isso não as levava em consideração, nem mesmo como hipóteses de trabalho - por meio de um procedimento exclusivamente situado no plano dos fatos (Fleishmann, 1977, p. 140).

${ }^{13}$ Uma sistemática negação das hipóteses que se utilizem de um determinado tipo ideal, imagino eu, pode levá-lo ao desuso. Isto não significa um "falseamento".

Temáticas, Campinas, 3(5/6):9-36, jan./dez. 1995 
Entretanto, acerca disso, ć crucial mencionar que, para Weber, tal verificação não parece ser definitiva, p. se, de acordo com os dados empíricos existentes, um conhecimento é considerado "objetivo", isto é, válido "para todos aqueles que querem a verdade", nada impede que dentro de algum tempo, diante do surgimento de novos fatos, documentos - e, nas ciências naturais, novos testes -, esse mesmo conhecimento deixe de ser válido. E é nesse sentido, acredito, que devem ser lidas declarações suas afirmando que os produtos da ciência tendem, com o tempo, a ser superados, e que "toda realização científica (...) pede para ser 'ultrapassada' e superada. Quem deseja servir à ciência tem que resignar-se a tal fato" (Weber, 1982, p. 164).

Assim, se pudermos resumir a posição de Weber acerca da objetividade do conhecimento, colocaríamos desta forma, p. (1) a realidade (natural ou social) é inesgotável e infinita; (2) todo conhecimento opera uma seleção do material empírico; (3) influem nessa seleção valores do cientista - o que implicaria relativismo e subjetivismo; (4) para que se tenha objetividade, deve-se julgar qualquer conhecimento proposto através (a) dos critérios formais, como o rigor e a clareza dos conceitos, (b) da "demonstrabilidade" ou eficácia dos conceitos e (c) da adequação desse conhecimento aos fatos empíricos conhecidos: passando por estas "provas", um conhecimento é declarado "objetivo", até o surgimento de evidência contrária. Os pontos (1) e (2) seriam as condições sob as quais todo conhecimento seria produzido; o ponto (3) remeteria ao "contexto da descoberta"; e o ponto (4) ao "contexto da validação". 14

${ }^{14}$ Esta é, evidentemente, uma reconstrução "típico-ideal" do argumento weberiano, que não se apresenta nesta forma "pura" em nenhum momento. De qualquer forma, tal reconstrução é bastante semelhante à que fazem autores como Parsons, Saint-Pierre, Rossi e mesmo Löwy, e me parece encontrar documentação clara o suficiente para ser considerada "válida".

Temáticas, Campinas, 3(5/6):9-36, jan./dez. 1995 
Essa distinção entre o contexto da descoberta e o da validação sofreu virulenta crítica de Pietro Rossi (1971), que serviu de base para que Michael Löwy (1987) e Saint-Pierre (1991) decretassem a falência da epistemologia weberiana. $\mathrm{O}$ argumento de Rossi é o de que a influência dos valores (por ele nomeados de "pressupostos axiológicos") não se restringe à delimitação do objeto ("a primeira etapa do processo científico"), isto é, ao contexto da descoberta, mas se dá também no que chamei de "contexto da validação": os valores, pois, influenciariam todo o processo cognitivo, implodindo a "objetividade" weberiana,

A referência a valores não pode limitar-se à primeira etapa do processo científico, que é a delimitação do campo de investigação. Pelo contrário, a referência aos pressupostos axiológicos se encontra em todas as etapas da investigação. Os pressupostos axiológicos determinam a orientação geral e as decisões metodológicas derivadas dela. $\mathrm{Na}$ forma de hipóteses explicativas, atuam também sobre o processo explicativo. E se é assim, a adoção de certos pressupostos axiológicos condicionará também, direta ou indiretamente, os resultados da investigação, o que Weber, precisamente, não queria admitir (Rossi, 1971, p. 67).

Seguindo Rossi, Hector Saint-Pierre acredita que os sistemas de valores influenciam não apenas a construção e na delimitação do objeto, mas também a construção do "esquema de prova" - e assim a "objetividade" dos enunciados não pode ser decretada:

Isso introduz uma certa dúvida a respeito da validade dos procedimentos como garantia da "objetividade" dos resultados. Na realidade, Weber nunca é claro quando se refere à 'comprovação empírica' tanto nos resultados quanto nos métodos (Saint-Pierre, 1991, p. 47. A ênfase é minha). 
Löwy, por sua vez, dispara afirmando que, se os valores influenciam as questões feitas pelos cientistas sociais, e as respostas dependem em larga medida destas mesmas questões, então os valores terminam por influenciar todo o processo de investigação.

Dos três autores, Saint-Pierre (cujo texto é mais exegético) é o único que não busca uma saída própria para o problema da objetividade do conhecimento.

Löwy e Rossi, percebendo o quanto a negação da objetividade do conhecimento tem de autocontraditória, procuram esquemas alternativos: este procura dar "uma nova significação" à objetividade weberiana, através da criação de normas que regulem a influência dos "pressupostos axiológicos" na pesquisa; aquele, procura apresentar seu modelo epistemológico com o recurso à noção de determinação social do conhecimento sociológico (que é, como indica o autor, de Lucien Goldmann).

Löwy, ao renegar peremptoriamente a objetividade do conhecimento em todo seu texto, chega mesmo a flertar com o relativismo. A própria noção de "determinação social do conhecimento sociológico" ficaria sujeita ao dilema do relativista, ou, como Popper prefere chamar, à "dupla personalidade intelectual": num primeiro momento afirma-se que todo conhecimento sociológico é socialmente determinado e que, portanto, tais conhecimentos não podem pretender-se objetivos (personalidade intelectual 1); num segundo momento, finge-se que tal raciocínio não se aplica ao próprio pensamento, e que, portanto, ele pode ser considerado o retrato objetivo desta "realidade epistemológica" (personalidade intelectual 2).

Para não cair nesse raciocínio contraditório, Löwy pretende assentar a "objetividade do conhecimento" nas possibilidades estruturais dadas às perspectivas de classe. Assim, a classe operária, que seria a última classe, que. pretenderia acabar com qualquer regime de dominação, necessitaria, mais que qualquer outra, da verdade, e seria dotada de uma "superioridade epis- 
temológica” (Löwy, 1987, p. 200): “(...) o ponto de vista do proletariado ć o horizonte científico de nossa ćpoca” (1987, p. 201).

As demais classes tenderiam, de uma forma ou de outra, a perder com a livre divulgação da verdade, pois seriam as beneficiadas com o sistema de dominação vigente. Assim, seu horizonte científico seria limitado em relação ao horizonte proletário. Criticarei essa proposta adiante.

Melhor opção fez, acredito, Pietro Rossi. Como esse autor parece querer defender a objetividade nas ciências sociais, ele trata de formular "regras estritas" para a utilização do que chamou de "pressupostos axiológicos” (ou valores), de modo a aprimorar as idéias weberianas. São elas:

1) é exigida a enunciação formal dos pressupostos;

2) as hipóteses de trabalho deles derivadas devem ser "postas à prova no curso da investigação";

3) os modelos explicativos emergentes devem ser conservados ou descartados conforme a experiência.

Segundo ele, a primeira regra impede que se confunda pressupostos com a realidade; a segunda estabelece o caráter hipotético dos pressupostos; a terceira estabelece que a experiência "é de uma importância decisiva para a adoção ou o afastamento de uma hipótese explicativa" (1971, p. 68). Rossi acredita ter dado outra significação para a objetividade weberiana.

Primeiramente, analisarei a crítica que os autores fazem a Weber. Rossi, Saint-Pierre e Löwy a mim parecem estar equivocados quando dão pouca importância à distinção entre o contexto da descoberta e o contexto da validação. Se os valores (ou "pressupostos axiológicos") efetivamente influenciam a construção do objeto de pesquisa e mesmo das hipóteses iniciais - isto é, se realmente atuam no contexto da descoberta -, não há por que acreditar que tenham vez no momento de se sub- 
meter à prova os resultados da pesquisa, p. tais resultados não serão analisados em um ambiente monista em termos de valores. É nesse sentido que Weber afirma que um conhecimento que se pretende válido deverá ser reconhecido como tal "mesmo por um chinês" - leia-se: mesmo por alguém que tenha outros valores (Weber, 1974, p. 23) -, ou "para todos os que querem a verdade" (1974, p. 66) - leia-se: independente dos valores que assumam para sua vida prática.

Além disso, as hipóteses históricas deverão ser "verificadas" empiricamente. E se Löwy está certo quando afirma que as questões feitas à realidade determinam as respostas que esta poderá dar, deve-se assinalar que essa determinação é "plástica": limita sobre o que "será respondido", e não o que se "responderá". Popper percebe isso bem quando afirma que

(...) embora os fatos sejam coligidos com vistas à teoria, e a confirmem enquanto a teoria se mantiver de pé em face dessas comprovações, são eles mais do que simplesmente uma espé. cie de repetição vazia de uma teoria pré-concebida. (...)

... uma descrição científica dependerá em ampla escala de nosso ponto de vista, nossos interesses (...); mas também de. penderá dos fatos descritos (Popper, 1980, p. 267. A ênfase é minha).

Assim, acredito que a distinção entre o contexto da descoberta e o contexto da validação é a arma teórica weberiana que não permite que sua epistemologia naufrague diante das ameaças relativistas. Concordo com Parsons quando esse afirma que

(...) as bases de interesse em função das quais se projetam os problemas de uma ciência devem ser distinguidas cuidadosamente dos critérios aplicados no que se refere aos métodos utilizados para resolver tais problemas, e da validade das proposições formuladas a partir do emprego desses métodos (Parsons, 1971, p. 8). 
Examinarei, agora, as "teorias epistemológicas" de Löwy e Rossi. A "teoria" da objetividade do conhecimento de Löwy não tem grandes atrativos, nem traz consigo motivos fortes para ser considerada ao menos um argumento razoável. Apesar de se basear cm autores de peso (Lucien Goldmann, Adam Schaff...), ${ }^{15}$ apresenta um raciocínio tortuoso que consiste em basear a objetividade de uma teoria (no caso, da teoria marxista) em fatos apresentados pela própria teoria (como a "superioridade epistemológica da classe proletária"). O argumento é mais ou menos o seguinte: (a) pela nossa teoria, existem classes revolucionárias; (b) pela nossa teoria é a classe revolucionária que tem o privilégio da verdade (ou da verdade maior); (c) pela nossa teoria, a classe revolucionária atual é o proletariado; (d) então, pela nossa teoria, quem fala a verdade é o proletariado, ou melhor, aqueles que defendem seus reais pontos de vista - isto é, nós. Para que esse verdadeiro imperialismo epistemológico fosse completo faltaria apenas dizer que, dentre aqueles que estão conosco, percebem melhor a verdade aqueles que concordam comigo.

O próprio Löwy admite, ao cabo, que a adesão aos argumentos da sua "epistemologia" é uma questão de fé:

(...) eles são aceitáveis apenas para os que já optaram, para aqueles que já tomaram posição a favor do proletariado e do seu ponto de vista. Em outros termos: eles contêm um núcleo irredutivel de fé, ou mais precisamente, de aposta histórica sobre o papel emancipador do proletariado, sobre a sua

${ }^{15}$ Cf. Löwy (1987), Goldmann, Les sciences humaines et la philosophie; Adam Schaff, Histoire et Verité. É dever elogiar o trabalho de Löwy pela gigantesca análise bibliográfica que faz, no mais das vezes, muito bem feita.

Temáticas, Campinas, 3(5/6):9-36, jan./dez. 1995 
vocação universal e redentora (Löwy, 1987, p. 201. A ênfase está no original). ${ }^{16}$

Em relação às regras propostas por Rossi, considero-as corretas do ponto de vista metodológico, mas acredito que Weber as adiantou e que, portanto, Rossi não deu "nova significação" alguma aos argumentos weberianos. Vejamos.

A exigência da enunciação formal dos pressupostos (primeira regra de Rossi) é muito próxima à exigência que faz Weber de distinguir entre o que é norma e o que é fato (Weber, 1992d, p. 370), o que é juízo de valor e o que é juízo de fato (1992b, p. 163). Mais precisamente, Weber admite que o cientista emita juízos de valor, explicitando, porém, "quais os padrões de valor com que se mede a realidade (...)" $(1974$, p. 25). A função declarada dessa primeira regra (impedir que se confunda pressupostos com a realidade) é fartamente cumprida por Weber, que inúmeras vezes faz questão de distinguir entre artefatos analíticos e realidade empírica (por exemplo, 1992d, p. 396; 1974, p. 83). Quanto às segunda e terceira regras de Rossi (pôr à prova as hipóteses e mantê-las ou descartá-las conforme a experiência), pode-se dizer que Weber também as adiantou: um conhecimento só pode ser considerado válido, como vimos, se "em caso de questionamento, saiu honroso da prova

${ }^{16}$ A teoria epistemológica de Löwy é, no meu entender, um claro exemplo de confusão entre a influência lógica dos valores na conformação da realidade e a influência prática dos valores (cf. mais acima). Assim, Löwy trabalha com conceitos como "classe operária" ou "interesses da classe operária" como se fossem claros o suficiente para deles não se exigir maiores predicados. Sua idéia de "interesses da classe trabalhadora" é ideal não no sentido lógico, pois, mas no prático: corresponde ela às aspirações políticas (legítimas, mas apenas na política) do autor. 
(...)" (1992b, p. 202). Acredito, pois, que Rossi subestimou a relativa sofisticação da epistemologia weberiana.

Para finalizar este artigo, remeto a dois tópicos relativos às questões que tratamos em Weber. O primeiro diz respeito à neutralidade axiológica e à confusão que se faz entre esta e a objetividade do conhecimento. Para nosso autor, "A ausência de doutrina e a 'objetividade' científica não têm qualquer parentesco interno." (1974, p. 26, ênfase no original). $\mathrm{O}$ autor apenas assinala que $a$ adesão desmedida a determinados valores pode inibir no cientista o necessário espírito crítico. ${ }^{17}$ No mais, o fato de um conhecimento ser útil a uma camada ou classe social específica não quer dizer que membros de outras camadas ou classes não possam reconhecer-lhe a verdade. ${ }^{18}$

Por fim, trato sumariamente da "possibilidade objetiva". Weber, como mencionado acima, não acredita que existam diferenças quanto a regras de validação entre as ciências sociais e naturais. Mas como Runciman argutamente assinala, para Weber, "o critério de validade comum ao naturalista e ao sociólogo não pressupõe nem requer um procedimento comum a ambos" (Runciman, 1976, p. 35, ênfase minha). Logo, a aceitação de um princípio de validação universal não implica aceitação irrestrita de técnicas derivadas das ciências naturais. Weber assinala que a história é um mau laboratório (1974, p. 94-6), e, na falta de uma ampla possibilidade de experimentações (existente de fato nas ciências natu-

${ }^{17}$ Cf., por exemplo, Weber (1982, p. 179), quando afirma que a adesão a valores religiosos implicam "sacrifício intelectual".

${ }^{18}$ Runciman (1976, p. 75) também parece querer diferenciar a objetividade de um conhecimento de sua neutralidade axiológica: mesmo aqueles que não concordam com eventuais pressupostos ou derivações valorativas de um conhecimento podem concordar acerca de sua validade (ou o contrário).

Temáticas, Campinas, 3(5/6):9-36, jan./dez. 1995 
rais), surge a idéia de possibilidade objetiva. Assim, na ausência de dados observacionais ou experimentais adequados,
(...) é avaliável apenas o procedimento perigoso e incerto do 'experimento imaginário' que consiste em imaginar certos elementos de uma cadeia motivacional e elaborar o curso da ação como ele provavelmente resultaria, chegando assim a um julgamento causal (Weber apud Hempel, 1965, p. 162).

Acredito, portanto, que Parsons (1968, p. 749) está certo quando considera a possibilidade objetiva como um "mecanismo de prova" ou "verificação" específico das ciências sociais. Tal mecanismo funcionaria da seguinte forma, p. monta-se um esquema explicativo hipotético em que se expõe o curso esperado dos acontecimentos caso os atores $\mathrm{cm}$ questão tivessem se comportado racionalmente; compara-se tal esquema com o que de fato aconteceu. Se o que aconteceu é igual ao esquema, então o esquema está correto; caso contrário, procura-se o que pode haver mudado no esquema de forma a participar da explicação como causa.

(...) o único modo de chegar a um juízo sobre o significado causal de um fator é perguntar pelo que haveria sucedido se o fator não estivesse presente ou fosse modificado (Parsons, 1968, p. 751).

A presença de regras de validação específicas das ciências sociais, então, não se torna problema para uma epistemologia que, longe de deixar de reconhecer as especificidades substantivas que marcam as diferenças entre as ciências sociais e as naturais, fez perceber que a questão da objetividade do conhecimento tem determinantes gerais (o contraste entre a infinitude do real e a parcialidade - e finitude - do conhecimento) que independem de tais especificidades.

Temáticas, Campinas, 3(5/6):9-36, jan./dez. 1995 


\section{REFERÊNCIAS BIBLIOGRÁFICAS}

COHN, Gabriel. Sociologia, para ler os clássicos. Rio de Janeiro, Livros Técnicos e Científicos, 1977.

. Crítica e Resignação: os fundamentos da sociologia de Max Weber. São Paulo, T. A. Queiroz, 1979.

DIAS, Edumundo F. "Para uma Introdução à Reflexão Weberiana". Textos Didáticos do IFCH, ${ }^{\circ} 1$. Campinas, 1993.

FLEISCHMANN, Eugène. "Weber e Nietzsche". In: Gabriel COHN (org.). Sociologia, p. Para Ler os Clássicos. Rio de Janeiro, Livros Técnicos e Científicos, 1977.

HEMPEL, Carl G. "Typological Methods in the Natural and the Social Sciences". In: Carl G. HEMPEL. Aspects og Scientific Explanation.

New York, The Free Press; London, Collier-MacMillan Limited, 1965.

JASPERS, Karl. "Método e Visão de Mundo em Weber". In: Gabriel COHN (org.). Sociologia, p. Para Ler os Clássicos. Rio de Janeiro, Livros Técnicos e Científicos, 1977.

LÖWY, Michael. As Aventuras de Karl Marx contra o Barão de Münchbausen: marxismo e positivismo na teoria do conbecimento. Tradução de Juarez Guimarães e Suzanne Léwy. São Paulo, Busca Vida, 1987.

PARSONS, Talcott. La Estructura de la Accion Social. Madrid, Ediciones Guadarrama, 1968.

- "Evaluación y Objetividad en el ámbito de las

Ciencias Sociales: una interpretación de los trabajos de Max Weber". In: Talcott PARSONS (et alli). Presencia de Max Weber. Buenos Aires, Ediciones Nueva Visión, 1971. 
POPPER, Karl R. A Miséria do Historicismo. Tradução de Octanny Mota e Leonidas Hegenberg. São Paulo, Cultrix $\backslash E d$. da USP, 1980.

- A Lógica da Pesquisa Científica. Tradução de Octanny Mota e Leonidas Hegenberg. São Paulo, Cultrix, 1989. RICKERT, Heinrich. "Max Weber's View of Science". In: LASSMAN \& VELOGY. Max Weber 'Science as a Vocation'. London, Unwin Hyman, 1989.

ROSSI, Pietro. “Objetividad Científica y Presupuestos Axiológicos". In: Talcott PARSONS (et alli). Presencia de Max Weber. Buenos Aires, Ediciones Nueva Visión, 1971.

RUNCIMAN, W.G. Critica de la Filosofia de las Ciencias Sociais de M. Weber. Mexico, Fondo de Cultura, 1976.

. Ciência Social e Teoria Política. Rio de Janeiro, Zahar, s/d.

SAINT-PIERRE, Héctor L. Max Weber: entre a paixão e a razão. Campinas, Ed. da UNICAMP, 1991.

SOARES, Jeferson B. Sobre a Lógica da Ciência Social Teórica, p. uma apresentação das propostas de Karl Popper. Dissertação de mestrado, FAFICH - UFMG, 1992.

WEBER, Max. "A Objetividade do Conhecimento nas Ciências e na Política Sociais". In: Sobre a Teoria das Ciências Sociais. Lisboa, Editorial Presença, 1974.

. "A Ciência como Vocação". In: GERTH E MILLS (org.). Ensaios de Sociologia. Rio de Janeiro, Guanabara, 1982.

. "Conceitos Sociológicos Fundamentais". In: Economia $e$ Sociedade. Brasília, Ed. da Unb, 1991.

- "Roscher e Knies e os Problemas Lógicos de Economia Política Histórica". In: Metodologia das Ciências Sociais. (2 volumes). São Paulo, Cortez; Campinas, Ed. da UNICAMP, 1992a. 
- "Estudos Críticos sobre a Lógicas das Ciências da Cultura". In: Metodologia das Ciências Sociais. (2 volumes). São Paulo, Cortez; Campinas, Ed. da UNICAMP, 1992b.

- "Stammler e a Superação da Concepção Materialista da História". In: Metodologia das Ciências Sociais. (2 volumes). São Paulo, Cortez; Campinas, Ed. da UNICAMP, 1992c.

- "O Sentido da 'Neutralidade Axiológica' nas Ciências Sociais e Econômicas". In: Metodologia das Ciências Sociais. (2 volumes). São Paulo, Cortez; Campinas, Ed. da UNICAMP, 1992d. 